\title{
Child Distributive Behavior and Inhibitory Control in a Private Context
}

\author{
Renata Mascarenhas Aleixo Reis ${ }^{1}$ (D) https://orcid.org/0000-0002-0840-4355 \\ Leonardo Rodrigues Sampaio² (D) https://orcid.org/0000-0003-2383-4094
}

\begin{abstract}
Several studies have sought to assess the cognitive aspects underlying the sharing of goods. This work aimed to evaluate whether there is a relationship between inhibitory control and distributive behavior in a private context (total anonymity of the distributor). One hundred and thirty-six children aged between three and 12 years participated in a dictatorial game and a standard Stroop task. Age, inhibitory control and distributive behavior were positively correlated, but only age was predictive of sharing. It is suggested that the moral reasoning employed in the distributive context explains this tendency, in which older children, when reflecting on resource sharing, resort to respect for social rules. In contrast, younger children feel that their desire is sufficient to justify the self-centered behavior, even knowing the rules. The results contribute to the field of child development by providing information that allows a better understanding of the role executive functions play in distributive decisions.
\end{abstract}

Keywords: moral development, childhood, self-control

\section{Comportamento Distributivo Infantil e Controle Inibitório em um Contexto Privado}

Resumo: Diversos estudos têm buscado avaliar os aspectos cognitivos subjacentes à partilha de bens. O presente trabalho teve por objetivo avaliar se existe relação entre controle inibitório e comportamento distributivo em contexto privado (total anonimato do distribuidor). Participaram de um jogo ditatorial e de uma tarefa padrão Stroop, 136 crianças entre três e 12 anos. A idade, o controle inibitório e o comportamento distributivo se correlacionaram positivamente, porém apenas a idade foi preditiva da partilha. Sugere-se que o raciocínio moral empregado no contexto distributivo explique esta tendência, onde crianças mais velhas, ao refletirem sobre divisão de recursos, recorrem ao respeito às regras sociais. Em contrapartida, as crianças mais novas julgam que seu desejo é suficiente para justificar o comportamento autocentrado, mesmo sabendo das regras. Os resultados contribuem para o campo de estudo do desenvolvimento infantil, fornecendo informações que permitam uma melhor compreensão a respeito do papel que funções executivas tem nas decisões distributivas.

Palavras-chave: desenvolvimento moral, infância, autocontrole

\section{Comportamiento Distributivo Infantil y Control Inhibitorio en un Contexto Privado}

\begin{abstract}
Resumen: Varios estudios han tratado de evaluar los aspectos cognitivos que subyacen al reparto de bienes. El presente estudio tuvo como objetivo evaluar si existe una relación entre el control inhibitorio y el comportamiento distributivo en un contexto privado (anonimato total del distribuidor). Participaron 136 niños entre 3 y 12 años de edad en un juego dictatorial y una tarea estándar Stroop. La edad, el control inhibitorio y el comportamiento distributivo se correlacionaron positivamente, mientras que solamente la edad fue predictiva para el reparto. Se sugiere que el razonamiento moral empleado en el contexto distributivo explica esta tendencia a que los niños mayores, al reflexionar sobre el reparto de recursos, recurren al respeto a las reglas sociales. En contraste, los niños más pequeños juzgan que su deseo es suficiente para justificar el comportamiento autocentrado, incluso sabiendo las reglas. Los resultados contribuyen al campo de estudio sobre el desarrollo infantil al proporcionar informaciones que permiten comprender mejor el rol que desempeñan las funciones ejecutivas en las decisiones distributivas.
\end{abstract}

Palabras clave: desarrollo moral, infancia, autocontrol

${ }^{1}$ Faculdade Adventista da Bahia, Cachoeira-BA, Brazil

${ }^{2}$ Universidade Federal do Vale do São Francisco, Petrolina-PE, Brazil

Paper derived from the master's dissertation of the first author under supervision of the second, defended in 2016, in the Graduate Program in Psychology, Universidade Federal do Vale do São Francisco - Petrolina. Support: This study received financial support from the State of Pernambuco Science and Technology Support Foundation. Process IBPG-0352-7.07/15. Acknowledgment: the authors thank Raick Bastos de Santana, Maria Lucicléa Barros and Victor Eugênio de Santana Costa for their collaboration in data collection.

Correspondence address: Renata Mascarenhas Aleixo Reis. FADBA, BR. 101, Km 197, Caixa postal 18, Capoeiruçu, Cachoeira-BA, Brazil. CEP 44.300-000. E-mail: mascarenhasaleixo@gmail.com
The ability to perform problem solving, task planning and execution, assessment and modification of one's own behavior against pre-established goals is associated with neurocognitive processes coordinated by the prefrontal cortex, called executive functions (Garcia-Barrera, Kamphaus, \&Bandalos,2011; Malloy-Diniz,Sedó,Fuentes, \&Leite,2008). One of the components of executive functions that play an important role in controlling behavioral responses that are inappropriate to the social context (Diamond, 2013) is Inhibitory Control, which enables the individual to control overriding responses, stopping individual impulses and 
postponing gratifications present in the here-now, to achieve better rewards in the future (Kidd, Palmeri, \& Aslin, 2013). Inhibitory control develops from genetic and sociocultural factors (Colzato et al., 2016; Sulik et al., 2015), as well as from the maturation process of the prefrontal cortex (Ordaz, Foran, Velanova, \& Luna, 2013).

During early childhood, inhibitory control develops rapidly and intensely but continues to develop until the beginning of adulthood, when it reaches the peak of its performance (Malloy-Diniz et al., 2008; Zelazo \& Carlson, 2012). Thus, younger children have greater difficulty inhibiting behavioral responses than adolescents and adults (Macdonald, Beaucham, Crigan, \& Anderson, 2014). For this reason, in early childhood they tend to exhibit more impulsive and egocentric behavior linked to their personal desires (Piazza, Bering, \& Ingram, 2011).

With advancing age, the role of regulating executive functions over social behavior increases (Best, Miller, \& Naglierie, 2011), so that children already begin to have more self-control of their actions, in addition to solving problems of their own daily context, taking into account cooperation and mutual respect contracts, as well as the moral norms in force in their group (Cushman, Sheketoff, Wharton, \& Carey, 2013; Decety, Michalska, \& Kinzler, 2012). In this perspective, neurological mechanisms that link implicit moral evaluations, such as cognitive reevaluation, are related to the construction of notions of justice and also guide the expression of cooperative behavior (Cowell \& Decety, 2015).

Studies on child distributional behavior have a long tradition in Developmental Psychology and show that the way children apply and judge norms of justice in contexts of distribution of goods changes throughout childhood (Blake \& Rand, 2010; Kogut, 2012). More specifically, in the process of moral sense development, children tend to use different principles of justice, such as equality, necessity, and equity, to evaluate and effect the division of goods (Sampaio, Camino, \& Roazzi, 2007).

In this sense, there is a tendency for egalitarian judgments to be more frequently used as children's age increases, with older children presenting a more aversive behavior to inequality and rejecting unfair offers in resourcesharing situations, even when this benefits them (McAuliffe, Blake, \& Warneken, 2014; Steinbeis \& Singer, 2013). These changes in child distributive behavior are due to both cognitive-affective factors, such as perspective taking (Chen, Zhu, \& Chen, 2013; Fehr, Glätzle-Rützler, \& Sutter, 2013), and socioeconomic and cultural factors (Rochat et al., 2009). In addition, manipulations in distribution contexts (e.g. experimenter presence, advantageous inequality, type of recipient, resource value, among others) are related to how children make decisions about sharing goods (Blake \& Rand, 2010; Moore, 2009; Sampaio \& Pires, 2015).

Regarding specifically the role that social clues (such as moral reputation and desirability) play in the way children make distributive decisions and their relationship with inhibitory control, the study by Smith, Blake, and Harris (2013) stands out. These authors believed that during a dictatorial game, while children recognized the importance of the norm of equality, they would not be able to inhibit their desire to keep most of the goods available (stickers) to themselves, as it involved a high personal cost, so that the child would have to give up the goods valued by him/ her. In this sense, failure to fully develop inhibitory control would lead younger children to behave more self-centeredly, ignoring the norm of equality and withholding more goods for themselves.

However, the results of the study by Smith et al. (2013) indicated no relationship between inhibitory control and sharing behavior between 3 and 8 years of age. This may have been due to a strong social desirability bias, as shown in previous studies, in which it was found that children of this age group tend to behave more fairly and equitably when being observed than when alone (Blake \& Rand, 2010; Piazza et al., 2011; Sampaio \& Pires, 2015).

More specifically, since in the study by Smith et al. (2013) children always performed the sharing of goods in the presence of the researcher (public context), it is possible that they were motivated to share more stickers, seeking to conform to a social demand to demonstrate egalitarian behavior, which would hide possible effects of inhibitory control over the desire to have more goods for themselves. According to the study by Sampaio and Pires (2015), the possibility of children to share goods alone and totally anonymously (the recipient would not know their identity) made them show a very strong tendency to keep a large number of stickers for themselves, when compared to those who performed the same task in a public context (the division of the stickers should be done in the presence of the researcher). This effect of the researcher's presence was especially important for older children (aged 6 to 8 years), who showed more willingness to equality than the other groups.

In recent studies, Cowell, Samek, List and Decety (2015) and Liu et al. (2016) also did not find any relationship between inhibitory control and sharing behavior. Although resource sharing was performed without the experimenter being present in both studies, it is unclear whether any instruction was given concerning the child's total anonymity to the recipient of their decisions, which may also influence the decision based on social desirability. On the other hand, Cowell et al. (2017) observed that executive functions predicted generosity in a study carried out with children aged between 5 and 12 years from different cultures. Aguilar-Pardo, Martínez-Arias, and Colmenares (2013) also observed that altruism (measured by willingness to donate their candies) and inhibitory control were positively correlated in children aged between 4 and 6 years. However, this relationship did not remain significant when the analysis was performed only with the subgroup of children who donated at least one candy.

Although these findings are important to understand distributive behavior in childhood, there is still few research that sought to investigate the relationships between distributive behavior and more general aspects of child cognition, especially those related to decision making, such as 
executive functions. Moreover, in view of the inconsistency in the results produced so far, as well as the methodological gaps pointed out above, we consider that it is not yet clear whether there are, in fact, relationships between inhibitory control and child distributive behavior.

In this sense, this study aimed to evaluate whether there is a relationship between inhibitory control and distributive behavior in a private context (total distributor anonymity), a distinctive characteristic regarding previous research. In addition, we sought to evaluate the relationship between these two variables and the age and sex of the participants.

We hypothesized that when children are "free" from the pressure exerted by social desirability and from the need to conform to standards that value equality, inhibitory control shall have a significant influence on sharing behavior, leading those with lower development levels in this ability to behave more self-centeredly. In addition, we assumed that the level of performance on the inhibitory control task will increase with advancing age, and the higher the level of inhibitory control, more sticker cards will be donated by children, even when no one is observing their behavior.

\section{Method}

\section{Participants}

One hundred and thirty-six children participated in this study ( $50.7 \%$ boys), aged between 3 and 12 years ( $M=93.39$ months, $S D=35.02$ ), belonging to three private schools from the city of Petrolina, state of Pernambuco, Brazil $(n=107)$ and two private schools from the city of Feira de Santana, state of Bahia, Brazil $(n=29)$. Only children who volunteered to participate in the study and whose parents or guardians signed the consent form were included in the sample. In addition, the following exclusion criteria were established: children diagnosed with learning disabilities/deficits, history of psychiatric, neurological, and motor disorders, or with some form of invasive developmental disorder.

\section{Instruments}

Sharing behavior was assessed through a dictatorial game that involved the distribution of sticker cards among the participant and a second child, which was actually fictitious, following the procedures employed in the study by Sampaio and Pires (2015). Disney ${ }^{\circledR}$ characters sticker cards and two colored envelopes were used to separate the stickers the participant kept (green) from those given to another child (orange). In addition, a blue envelope, which belonged to a child who supposedly played with the researcher before, was used to assess participants' expectations regarding other children's sharing behavior. A five-level graphical Likert scale (Smiley faces) $(1=$ very sad and $5=$ very happy $)$ was used to assess how happy children would be if they won four sticker cards.

To assess inhibitory control, a response inhibition task called Stroop Day and Night was used, according to the procedures described by Gerstadt, Hong, and Diamond(1994), in two versions adapted by Natale, Teodoro, Barreto and Haase (2008). The two versions of Stroop's task were viewed on a notebook (Dell Inspiron 14 3421-A10; Core i3, 14 inches) through a presentation previously developed in the Microsoft ${ }^{\circledR}$ Powerpoint ${ }^{\circledR}$ software 2003. In this, the researcher clicked play and automatically the images were presented on the notebook screen, in a pseudo-random order and with the time of passage from one image to another digitally standardized ( 2 seconds, 1 second with the still image and 1 second of transition between images).

The first version of the task is called "Day-Night" and has two models: the first with images of a clear blue sky with white clouds and the sun, representing the day; the second with images of the dark sky with the moon and stars, representing the night. The second version is called "Abstract", also composed of two image models, but with non-identical abstract designs (geometric figures and traces forming a grid in some regions). In one image, the figure is colored red with a blue "day" background, while the other image is blue with a red "night" background. The moment the stimulus is viewed, the child is instructed to say "day" whenever a particular image model appears and to say "night" to the second model.

In each version, the two image models were presented nine times in a predetermined order, totaling a sequence of 18 images. The first two images of both versions were fixed and a picture of each model was presented. Participants' hits on both versions were noted in an answer sheet.

\section{Procedure}

Data collection. Data collection was performed by four researchers, who individually applied the dictatorial game and the Stroop test with each participant, in a single session, in empty classrooms of the school where the children studied. The order of performance of the two instruments was alternated between participants to avoid possible ordering effects.

At the beginning of the dictatorial game, the satisfaction degree concerning the stickers by the children was tested using the graphic Likert scale with Smiley faces. Then the researcher would give four sticker cards to the participant and say: "All four of these sticker cards belong to you. After you, another child will come play with me, but will not get any stickers. Then, if you wish, you can give some of these cards to this other child. But remember, the cards are yours, you can give as many as you like or you can choose not to give any. I will leave the room and I will not know how many cards you gave away. The child who will play after you will not know who you are either." Thus, the participant was instructed to put in the green envelope the amount of cards he wanted to keep for himself and in the orange envelope the amount he wanted to share. The researcher would then leave the room until the participant completed the task.

After returning to the room, the researcher would show the child a blue envelope and say: "This envelope belonged to another child who played with me before and who also 
got four sticker cards, just like you. He could also decide whether or not to leave some cards, even without knowing who you are. How many sticker cards do you think the other child who came to play with me before should have left for you?" This second part of the task made it possible to compare children's actual sharing behavior with their distributive judgments about others.

In the Stroop test, initially, the child learned to name the images correctly, identifying the ones that represented the "day" and the "night" and the researcher said that they would play with the cards, as people do in the "Against Land". That is, whenever the "day" card appears, the child should say "night" and vice versa. The training procedure was repeated until the child gave two correct answers in sequence to the presentation of the two image models. When noting that the child had understood the instructions, the researcher would press play to begin the presentation and then write down the answers, giving one point for each hit. Failure to respond to an image or giving a response that did not match the instructions were considered errors.

Data analysis. Initially, the Kolmogorov-Smirnov test indicated that the data did not follow a normal distribution, leading to the decision to use nonparametric tests for inferential analyses. Then, the Kruskal-Wallis test and the Mann-Whitney test (employed as post-hoc test) evaluated whether the valuation of the stickers, the number of stickers donated and expected, and the amount of Stroop hits were influenced by the applicator, sex, age, and distributive behavior (prosocial or self-centered) of the participants. Pearson's chi-square test was used to compare the percentages of prosocial and self-centered children according to age. Finally, Spearman's test was performed to evaluate the existence of correlations between the number of stickers donated and expected, the hits on the Stroop task, and the age of the children. In addition, a logistic regression analysis was performed to assess the likelihood of self-centered or prosocial behavior as a function of the values assumed by age and by hits in the Stroop task. The variables for the model were selected by the forward stepwise method, entered one at a time and with the first one having the highest correlation with the dependent variable (Hair, Black, Babin, Anderson, \& Tatham, 2009).

\section{Ethical Considerations}

This research complied with the ethical requirements of Resolution 422/12 of the National Health Council, and was approved by the Research with Human Beings Ethics Committee of the Universidade Federal do Vale do São Francisco (protocol No.: 55012516.9.0000.5196) before its realization.

\section{Results}

Fifteen protocols were excluded from the data analysis because there were measurement errors, children's lack of interest in starting or finishing the task or not understanding the activity, resulting in a final sample of 121 participants $(50.4 \%$ boys), who, for analysis purposes, were divided into five age groups: (1): 38-54 months (3-4 years, $n=19 ; M=49$ months; $S D=6.4 ; 57.8 \%$ boys); (2): $60-83$ months (5-6 years, $n=26$; $M=71.3$ months; $S D=5.6 ; 50 \%$ boys); (3): $84-107$ months (7-8 years, $n=27 ; M=95.3$ months; $S D=6.9 ; 44.4 \%$ boys); (4): 108-131 months (9-10 years, $n=22 ; M=119.2$ months; $S D=7.4 ; 31.8 \%$ boys); and (5): $132-155$ months (11-12 years, $n=27 ; M=144.4$ months; $D P=6.2 ; 66.6 \%$ boys).

Regarding the Smiley faces scale, participants generally showed good acceptance of the stickers $(M=4.68 ; S D=0.48)$, with no significant differences between age groups, as tested by the Kruskal-Wallis test (Table 1). This same test indicated that there were no significant differences in children's behavior and distributional expectations, as well as in Stroop performance, depending on the applicator who collected the data $(p>0.05)$.

Age influenced the number of stickers donated $(H=29.95 ; g l=4 ; p<0.001)$ and expected $(H=29.14$; $g l=4 ; p<0.001$ ) (Table 1). Regarding donated stickers, the Mann-Whitney $\mathrm{U}$ test indicated significant differences between groups $\mathrm{G} 1$ and $\mathrm{G} 5 .(U=70.5 ; p<0.001)$; $\mathrm{G} 1$ and $\mathrm{G} 4(U=92 ; p<0.001)$; $\mathrm{G} 2$ and $\mathrm{G} 5(\mathrm{U}=158.5 ; p<0.001)$; G3 and G5 $(U=155.5 ; p<0.001)$; and between G4 and G5 $(U=177 ; p=0.01)$. As for the expected stickers, the $U$ test pointed to the existence of significative differences between groups $\mathrm{G} 1$ and $\mathrm{G} 3(U=138 ; p=0.006) ; \mathrm{G} 1$ and G4 $(U=78.5 ; p<0.001)$; $\mathrm{G} 1$ and $\mathrm{G} 5(U=80.5 ; p<0.001)$; $\mathrm{G} 2$ and $\mathrm{G} 4(U=164.5 ; p=0.009) ; \mathrm{G} 2$ and $\mathrm{G} 5(U=187$; $p=0.002)$; and $\mathrm{G} 3$ and $\mathrm{G} 5(U=251 ; p=0.03)$.

Table 1

Means (standard deviation) of the satisfaction degree with the stickers, donated stickers, expected stickers, and Stroop hits in function of age

\begin{tabular}{lccccc}
\hline & G1 & G2 & G3 & G4 & G5 \\
\hline Satisfaction & $4.53(0.51)$ & $4.92(0.27)$ & $4.96(0.19)$ & $4.50(0.59)$ & $4.41(0.50)$ \\
Donation & $0.68(1.00)$ & $1.15(1.15)$ & $1.15(0.86)$ & $1.64(0.79)$ & $2.37(1.04)$ \\
Expectation & $2.84(1.21)$ & $2.50(1.39)$ & $1.93(0.91)$ & $1.45(0.91)$ & $1.37(0.62)$ \\
Hits & $22.42(8.28)$ & $29.31(5.57)$ & $33.19(2.93)$ & $33.95(4.20)$ & $35.07(1.35)$ \\
\hline
\end{tabular}

Note. G1 = 3-4 years; G2 = 5-6 years; G3 = 7-8 years; G4 = 9-10 years; G5 = 11-12 years. 
To deepen the analysis of children's distributive behavior patterns, their responses were classified as self-centered (the child donated no sticker cards) or prosocial (when at least one sticker card was donated). Overall, most children $(n=91)$ demonstrated prosocial behavior.

We also observed that children considered self-centered expected to earn more stickers from the "previous child" $(M=2.8 ; S D=1.24)$ than prosocial ones $(M=1.71 ; S D=1)$ and that the difference between these two means was significant $(H=18.62 ; g l=1 ; p<0.001)$. As shown in Figure 1 , a decrease in the frequency of self-centered behavior and an increase in prosocial behavior was observed as a function of the children's age $\left(\chi^{2}=34.09 ; g l=4 ; \mathrm{p}<0.001\right)$.

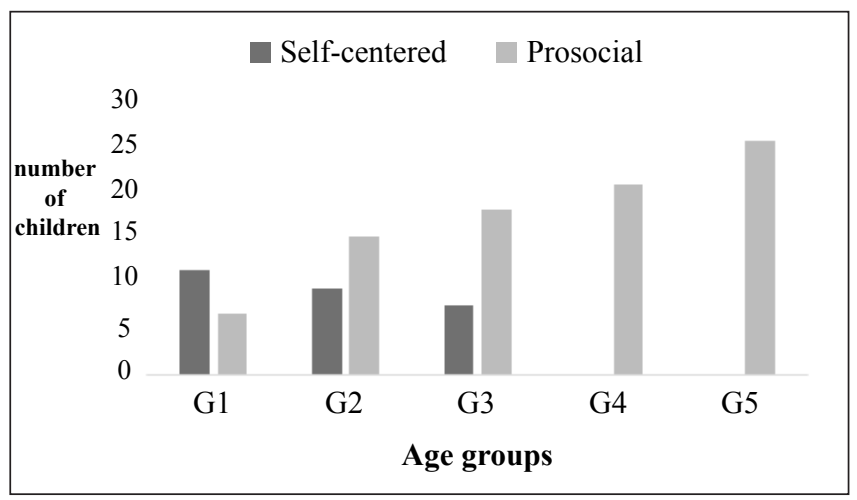

Note. $G 1=3$ and 4 years; $G 2=5$ and 6 years; $G 3=7$ and 8 years; $G 4=9$ and 10 years; $G 5=11$ and 12 years.

Figure 1. Frequencies of self-centered and prosocial children in each age group.

When comparing the averages of donated stickers only among children considered prosocial, significant differences were observed as a function of age $(H=9.22 ; g l=4 ; p=0.05)$, with an increase in the amount of donated sticker cards as age advanced. Regarding the Stroop task, participants achieved an overall mean of $31.22(S D=6.38)$ hits, and this number was influenced by age $(\mathrm{H}=52.38 ; \mathrm{gl}=4 ; \mathrm{p}<0.001)$. G1 had less hits than the other groups ( $\mathrm{G} 1$ and $\mathrm{G} 2$ : $\mathrm{U}=123$; $\mathrm{p}<0.001$; $\mathrm{G} 1$ and $\mathrm{G} 3: \mathrm{U}=56.5 ; \mathrm{p}<0.001$; G1 and G4: $\mathrm{U}=40 ; \mathrm{p}<0.001$; $\mathrm{G} 1$ and $\mathrm{G} 5: \mathrm{U}=24 ; \mathrm{p}<.001)$. $\mathrm{G} 2$ also has less hits than older age groups (G2 and G3: $\mathrm{U}=192$; $\mathrm{p}=0.004 ; \mathrm{G} 2$ and $\mathrm{G} 4: \mathrm{U}=101.5 ; \mathrm{p}<0.001 ; \mathrm{G} 2$ and $\mathrm{G} 5$ : $\mathrm{U}=84.5 ; \mathrm{p}<0.001)$. In addition, significant differences were found between groups G3 and G5 $(\mathrm{U}=201 ; \mathrm{p}=0.003)$.

Concerning the relationship between distributive behavior and inhibitory control, we observed that selfcentered children $(M=27.27 ; S D=7.68)$ made less hits than prosocial children $(M=32.53, S D=5.32)$ in the Stroop test $(H=19.31 ; g l=1 ; \mathrm{p}<0.001)$. The analyses also indicated that there were no significant differences between boys and girls in the number of stickers donated and expected or in the Stroop task performance $(p>0.05)$.

Spearman's test showed positive correlations between donated stickers and hits in the Stroop task $(\rho=0.34$, $\mathrm{p}<0.001)$, between donated stickers and age $(\rho=0.47$, $p<0.001$ ), and between hits on the Stroop task and age $(\rho=0.67, p<0.001)$. On the other hand, the number of stickers expected correlated negatively with donated stickers $(\rho=-0.29, p=0.001)$, with hits in the Stroop task $(\rho=-0.35, p<0.001)$, and with age in months $(\rho=-0.43$, $\mathrm{p}<0.001)$.

Finally, a regression analysis was performed to assess the predictivevalue ofageandhitsinStrooponthenumberofstickers donated (Table 2), considering the results of previous studies regarding the following aspects: (a) increased sharing in agerelated economic games situations (Blake \& McAuliffe, 2011; McAuliffeetal.,2014;Sampaio\&Pires,2015;Smithetal.,2013); (b) the role that inhibitory control plays in delaying gratifications (Kidd et al., 2013), thus contributing to increased altruistic behaviors (Aguilar-Pardo et al., 2013).

Regression analysis revealed that the model explained a significant amount of the variance of distributive behavior $(F(2.118)=20.91, p<0.001)$. However, the only variable that was significantly predictive of sharing was the age (in months) of participants.

Table 2

Regression analysis summary using distributive behavior as criterion variable and age and Stroop hits as predictor variables

\begin{tabular}{lccc}
\hline Variable analyzed & $\beta$ & $\mathrm{t}$ & $p$ \\
\hline Age in months & 0.47 & 4.62 & 0.000 \\
Hits in Stroop & 0.05 & 0.52 & 0.602 \\
\hline Note $\mathrm{R}^{2}$ adjusted $=0.24, \mathrm{~F}(2.118)=20.91, p<0.001$ &
\end{tabular}

Note. $\mathrm{R}^{2}$ adjusted $=0.24, \mathrm{~F}(2.118)=20.91, p<0.001$.

\section{Discussion}

This study aimed to evaluate whether there is a relationship between inhibitory control and distributive behavior in a private context. In addition, we sought to evaluate the relationship between these two variables and the age and sex of the participants.

Although other research have already pointed to the non-existence of the influence of inhibitory control on child distributive behavior (Aguilar-Pardo et al., 2013; Liu et al., 2016; Smith et al., 2013), this is the first study in which the effect of social desirability as an intervening variable was controlled, by allowing children to make their distributive decisions in a completely private context.

The results showed that older children donated more stickers than younger ones, and this may have occurred precisely because the group of more self-centered children (mostly younger ones) resorted to their own desires when deciding not to share the goods they had won in the Dictatorial Game. On the other hand, around the age of eight, children seem to guide their distributive decisions based on social norms and agreements, giving up their personal desires in favor of an equality that benefits others, as suggested by Blake and Rand (2010).

As noted in previous studies, the intensity of motivation to give in an equal manner increases from greater respect 
for the norms of justice and tends to peak at around the age of eight (Blake \& McAuliffe, 2011; Smith et al., 2013). This developmental trend may help explain why Blake and Rand's (2010) study found no significant differences in the number of stickers donated by children considered prosocial in function of age, as this experiment tested only children aged up to the six years.

A considerable difference between the expectation that the children had about the other child's distributive behavior and their own behavior was found, in agreement with the results of Sampaio and Pires (2015). In general, participants hoped that the child who played earlier left more cards than the ones they donated themselves. This discrepancy was even more evident when expectations of receiving stickers were compared based on their own distributive behavior, as the group that did not donate any stickers expected to win more cards from the previous child than the group that donated at least one. That is, younger children recognize the standards of fairness and apply equality norms related to sharing for others, but in similar situations, they act in contradiction with those norms because it involves a cost to themselves. Thus, in situations of conflict between norms and the desire to keep the goods, they would rather benefit themselves than following what would be socially expected/desirable (Smith et al., 2013).

Similar to the study by Sampaio and Pires (2015), we did not find any significant difference in the sharing behavior considering sex. Some studies found that girls tend to be more generous than boys in tasks that involve sharing (Aguilar-Pardo et al., 2013; Gummerum, Hanoch, Keller, Parsons, \& Hummel, 2010). However, it is important to highlight that in these studies, the age of the children was between 3 and 6 years, so that the differences found between sexes may be limited to some age groups, as shown by the study by Malti, Gummerum, Keller, Chaparro, and Buchmann. (2012), in which girls shared more stickers than boys, at ages 6 and 7 , however this difference no longer occurred at age 9.

Regarding inhibitory control, the results indicated an effect of age on Stroop task performance, demonstrating that the number of hits increased with advancing age. Previous studies havealso found similarresults regarding age(Cragg \& Nation, 2008; Lemes \& Rossini, 2014), demonstrating that inhibitory capacity gradually increases over human development (Best et al., 2011) in function of the maturation process of the prefrontal cortex and of social consequences, which may be reinforcing or punitive (Ordaz et al., 2013). This development begins in the first year of life and becomes more intense between six and eight years of age, reaching its peak in adulthood (MalloyDiniz et al., 2008). Such an universal pattern of executive function development between childhood and adolescence may help explain the fact that there were no significant differences between boys and girls in the Stroop task (Lemes \& Rossini, 2014).

The results pointed to a positive correlation between inhibitory control and distributive behavior, but regression analysis showed that this relationship may have occurred, in fact, by a third independent variable, age. Concerning this issue, Smith et al. (2013) explain that, possibly, what determines the increase in sharing as age advances is the development of respect for equality rules in decisive situations between desire and norms. Thus, it would not be theinhibitory control that preventchildren from fulfilling their desire in favor of norms, but rather the moral reasoning that children employ in making sharing decisions, causing older children to, when reflecting on the division of resources, follow the rules of justice. On the other hand, younger children would consider that only their desire is sufficient to justify their distributive behavior, even if they have knowledge of equality norms.

This study's results did not indicate the influence of inhibitory control on the ability of children to stop this possible desire to the point of causing them to give up the goods they gained freely (stickers). In this regard, it can be assumed that the force of social norms does not seem to be valid for the younger ones, probably because they have not yet built a morality more focused on social benefit, but rather in the pursuit of greater benefits for themselves, in such a way that inhibitory control is unable to act. This hypothesis is in line with the theoretical assumptions about morality in the field of justice by authors such as Damon (1980) and Piaget (1932/1994). However, further investigations into the relationship between distributive behavior and respect for social rules are still needed to test it empirically.

Although the regression model indicated that inhibitory control was not predictive of sharing behavior, the performance of prosocial children was better than that of self-centered children in the Stroop task. This may be an indication that prosocial distributive behavior demands more complex moral reasoning, so that sociomoral development could function as a promoter of sociocognitive development by stimulating executive functions. In this perspective, as children get older, social demands on the norms of justice become stronger and may reinforce the development of inhibitory control so that they can regulate their actions in compliance with those norms.

However, the exact nature of the relationship between inhibitory control and distributive behavior is still unclear, and future research are needed to continue to manipulate some variables of the distribution context, such as, for instance, the amount of stickers, to see if any significant effects of inhibitory control manifest. In addition, future studies may use hypothetical dilemmas (especially those involving rules of justice) to assess moral judgment in different age groups and their relationship with distribution of goods in a real situation, such as the one employed in this research.

Regarding the limitations of the study, it is noteworthy that the sample was of convenience and counted only with children from the private school system, which prevented a greater external validity of the results. Another possible limitation is related to the inhibitory control assessment instrument, 
since the average of hits in this task almost reached the ceiling effect around 11 years of age. In addition, the time elapsed between the presentation of the stimulus and the verbal response of each child was not recorded, limiting the possibilities of evaluating inhibitory control in this type of task.

In this sense, new studies can compare children from different socioeconomic levels and use other measures to evaluate response time in tasks of the Stroop type, to verify if the speed of accurate responses can also be a good indicator of inhibitory control ability. Another suggestion would be to use a different distributive situation, as the dictatorial game, in a sense, encourages self-centered behavior, as the individual unexpectedly earns his or her goods, and there is no commitment or incentive for them to give them up. On the contrary, it is made clear that they can freely do as they please. Therefore, it is possible that in situations where there is a possibility of cooperative interaction with others, inhibitory control has a significant influence on how the child distributes his or her possessions.

\section{References}

Aguilar-Pardo, D., Martínez-Arias, R., \& Colmenares, F. (2013). The role of inhibition in young children's altruistic behaviour. Cognitive Processing, 14(3), 301307. doi:10.1007/s10339-013-0552-6

Best, J. R., Miller, P. H., \& Naglieri, J. A. (2011). Relations between executive function and academic achievement from ages 5 to 17 in a large, representative national sample. Learning and Individual Differences, 21(4), 327-336. doi:10.1016/j.lindif.2011.01.007

Blake, P. R., \& McAuliffe, K. (2011). "I had so much it didn't seem fair": Eight-year-olds reject two forms of inequity. Cognition, 120(2), 215-224. doi:10.1016/j.cognition.2011.04.006

Blake, P. R., \& Rand, D. G. (2010). Currency value moderates equity preference among young children. Evolution and Human Behavior, 31(3), 210-218. doi:10.1016/j. evolhumbehav.2009.06.012

Chen, Y., Zhu, L., \& Chen, Z. (2013). Family income affects children's altruistic behavior in the Dictator Game. PLoS One, 8(11), e80419. doi:10.1371/journal.pone.0080419

Colzato, L. S., Steenbergen, L., Sellaro, R., Stock,A. K., Arning, L., \& Beste, C. (2016). Effects of L-Tyrosine on working memory and inhibitory control are determined by DRD2 genotypes: A randomized controlled trial. Cortex, 82, 217 224. doi:10.1016/j.cortex.2016.06.010

Cowell, J. M., \& Decety, J. (2015). The neuroscience of implicit moral evaluation and its relation to generosity in early childhood. Current Biology, 25(1), 93-97. doi:10.1016/j.cub.2014.11.002
Cowell, J. M., Lee, K., Malcolm-Smith, S., Selcuk, B., Zhou, X., \& Decety, J. (2017). The development of generosity and moral cognition across five cultures. Developmental Science, 20(4), e12403 doi:10.1111/desc.12403

Cowell, J. M., Samek, A., List, J., \& Decety, J. (2015). The curious relation between theory of mind and sharing in preschool age children. PLoS One, 10(2), e0117947. doi:10.1371/journal.pone.0117947

Cragg, L., \& Nation, K. (2008). Go or no-go? Developmental improvements in the efficiency of response inhibition in midchildhood. Developmental Science, 11(6), 819-827. doi:10.1111/j.1467-7687.2008.00730.x

Cushman, F., Sheketoff, R., Wharton, S., \& Carey, S. (2013). The development of intent-based moral judgment. Cognition, 127(1), 6-21. doi:10.1016/j. cognition.2012.11.008

Damon, W. (1980). Patterns of change in children's social reasoning: A two-year longitudinal study. Child Development, 51(4), 1010-1017. doi:10.2307/1129538

Decety, J., Michalska, K. J., \& Kinzler, K. D. (2012). The contribution of emotion and cognition to moral sensitivity: A neurodevelopmental study. Cerebral Cortex, 22(1), 209-220. doi:10.1093/cercor/bhr111

Diamond, A. (2013). Executive functions. Annual Review of Psychology, 64, 135-168. doi:10.1146/annurevpsych-113011-143750

Fehr, E., Glätzle-Rützler, D., \& Sutter, M. (2013). The development of egalitarianism, altruism, spite and parochialism in childhood and adolescence. European Economic Review, 64, 369-383. doi:10.1016/j.euroecorev.2013.09.006

Garcia-Barrera, M. A., Kamphaus, R. W., \& Bandalos, D. (2011). Theoretical and statistical derivation of a screener for the behavioral assessment of executive functions in children. Psychological Assessment, 23(1), 64-79. doi:10.1037/a0021097

Gerstadt, C. L., Hong, Y. J., \& Diamond, A. (1994). The relationship between cognition and action: Performance of children 3 1/2-7 years old on a stroop-like day-night test. Cognition, 53(2), 129-153. doi:10.1016/0010-0277(94)90068-X

Gummerum, M., Hanoch, Y., Keller, M., Parsons, K., \& Hummel, A. (2010). Preschoolers' allocations in the dictator game: The role of moral emotions. Journal of Economic Psychology, 31(1), 25-34. doi:10.1016/j.joep.2009.09.002

Hair, J. F., Jr., Black, W. C., Babin, B. J., Anderson, R. E., \& Tatham, R. L. (2009). Análise multivariada de dados [Multivariate data analysis] (A. D. Sant'Anna, Trans., 6th ed.). Porto Alegre, RS: Bookman. 
Kidd, C., Palmeri, H., \& Aslin, R. N. (2013). Rational snacking: Young children's decision-making on the marshmallow task is moderated by beliefs about environmental reliability. Cognition, 126(1), 109-114. doi:10.1016/j.cognition.2012.08.004

Kogut, T. (2012). Knowing what I should, doing what I want: From selfishness to inequity aversion in young children's sharing behavior. Journal of Economic Psychology, 33(1), 226-236. doi:10.1016/j.joep.2011.10.003

Lemes, P., \& Rossini, J. C. (2014). Atenção e comportamento inibitório em crianças de 6 a 8 anos [Attention and inhibitory behavior in children aged 6 to 8 years]. Psicologia: Teoria e Pesquisa, 30(4), 385-391. doi:10.1590/s0102-37722014000400003

Liu, B., Huang, Z., Xu, G., Jin, Y., Chen, Y., Li, X., Song, S., \& Jing. J. (2016). Altruistic sharing behavior in children: Role of theory of mind and inhibitory control. Journal of Experimental Child Psychology, 141, 222228. doi:10.1016/j.jecp.2015.09.010

Macdonald, J. A., Beauchamp, M. H., Crigan, J. A., \& Anderson, P. J. (2014). Age-related differences in inhibitory control in the early school years. Child Neuropsychology, 20(5), 509-526. doi:10.1080/09297049.2013.822060

Malloy-Diniz, L. F., Sedó, M., Fuentes, D., \& Leite, W. B. (2008). Neuropsicologia das funções executivas [Neuropsychology of executive functions]. In D. Fuentes, L. F. Malloy-Diniz, C. H. P. Camargo, \& R. M. Cosenza (Orgs.), Neuropsicologia: Teoria e prática [Neuropsychology: Theory and practice] (pp. 187-206). Porto Alegre, RS: Artmed.

Malti, T., Gummerum, M., Keller, M., Chaparro, M. P., \& Buchmann, M. (2012). Early sympathy and social acceptance predict the development of sharing in children. PLoS One, 7(12), e52017. doi:10.1371/journal. pone. 0052017

McAuliffe, K., Blake, P. R., \& Warneken, F. (2014). Children reject inequity out of spite. Biology Letters, 10(12), 20140743. doi:10.1098/rsbl.2014.0743

Moore, C. (2009). Fairness in children's resource allocation depends on the recipient. Psychological Science, 20(8), 944-948. doi:10.1111/j.1467-9280.2009.02378.x

Natale, L. L., Teodoro, M. L. M., Barreto, G. V., \& Haase, V. G. (2008). Propriedades psicométricas de tarefas para avaliar funções executivas em pré-escolares [Psychometric properties of tasks to evaluate executive functions in preschoolers]. Psicologia em Pesquisa, 2(2), 23-35. Retrieved from http://pepsic.bvsalud.org/scielo. php?script=sci_arttext\&pid=S1982-12472008000200004

Ordaz, S. J., Foran, W., Velanova, K., \& Luna, B. (2013). Longitudinal growth curves of brain function underlying inhibitory control through adolescence. The Journal of Neuroscience, 33(46), 18109-18124. doi:10.1523/JNEUROSCI.1741-13.2013
Piaget, J. (1994). The moral judgment of the child. New York, NY: Free Press. (Original work published 1932).

Piazza, J., Bering, J. M., \& Ingram, G. (2011), "Princess Alice is watching you": Children's belief in an invisible person inhibits cheating. Journal of Experimental ChildPsychology, 109(3), 311-320. doi:10.1016/j.jecp.2011.02.003

Rochat,P.,Dias,M.D.G.,Guo,L.,Broesch,T.,Passos-Ferreira, C., Winning, A., \& Berg, B. (2009). Fairness in distributive justice by 3-and 5-year-olds across seven cultures. Journal of Cross-Cultural Psychology, 40(3), 416-442. doi:10.1177/0022022109332844

Sampaio, L. R., Camino, C. P. S., \& Roazzi, A. (2007). Justiça distributiva em crianças de 5 a 10 anos de idade [Distributive justice in children aged 5 to 10 years]. Psicologia: Reflexão e Crítica, 20(2), 197-204. doi:10.1590/S0102-79722007000200004

Sampaio, L. R., \& Pires, M. F. D. N. (2015). Sharing in private and public situations: Does this really matter for children? The Spanish Journal of Psychology, 18, E42. doi:10.1017/sjp.2015.45

Smith, C. E., Blake, P. R., \& Harris, P. L. (2013). I should but I won't: Why young children endorse norms of fair sharing but do not follow them. PLoS One, 8(3), e59510. doi:10.1371/journal.pone.0059510

Steinbeis, N., \& Singer, T. (2013). The effects of social comparison on social emotions and behavior during childhood: The ontogeny of envy and Schadenfreude predicts developmental changes in equity-related decisions. Journal of Experimental Child Psychology, 115(1), 198-209. doi:10.1016/j.jecp.2012.11.009

Sulik, M. J., Eisenberg, N., Spinrad, T. L., LemeryChalfant, K., Swann, G., Silva, K. M., ... Verrelli, B. C. (2015). Interactions among catechol-Omethyltransferase genotype, parenting, and sex predict children's internalizing symptoms and inhibitory control: Evidence for differential susceptibility. Development and Psychopathology, 27(3), 709-723. doi:10.1017/S0954579414000807

Zelazo, P. D., \& Carlson, S. M. (2012). Hot and cool executive function in childhood and adolescence: Development and plasticity. Child Development Perspectives, 6(4), 354360. doi:10.1111/j.1750-8606.2012.00246.x

Renata Mascarenhas Aleixo Reis is a Professor of the Faculdade Adventista da Bahia, Cachoeira-BA, Brazil.

Leonardo Rodrigues Sampaio is a Professor of the Universidade Federal do Vale do São Francisco, PetrolinaPetrolina-PE, Brazil. 
Reis, R. M. A., \& Sampaio, L. R. (2019). Distributive Behavior and Inhibitory Control.

Authors' Contribution:

All authors made substantial contributions to the conception and design of this study, to data analysis and interpretation, and to the manuscript revision and approval of the final version. All the authors assume public responsibility for the content of the manuscript.

Received: Oct. 18, 2017

1st Revision: Mar. 01, 2018

2nd Revision: May. 02, 2018

3rd Revision: May. 28, 2018

Approved: Jul. 06, 2018

How to cite this article:

Reis, R. M. A., \& Sampaio, L. R. (2019). Child distributive behavior and inhibitory control in a private context. Paidéia (Ribeirão Preto), 29, e2933. doi: http://dx.doi.org/ 10.1590/1982-4327e2933 